\title{
Performance evaluation of a dual fuel engine (Diesel + LPG)
}

\author{
G.A. Rao', A.V.S. Raju' ${ }^{2}$ K. Govinda Rajulu ${ }^{3}$ and C.V. Mohan Rao ${ }^{4}$ \\ ${ }^{1}$ Dr.Paul Raj Engineering College, Bhadrachalam, Dist.Khammam-507111 (A.P.), India \\ ${ }^{2}$ Department of Mechanical Engineering, JNTU, Hydeerabad-500085 (A.P.), India \\ ${ }^{3}$ Department of Mechanical Engineerng, JNTU, Anantapur-515002 (A.P.), India \\ ${ }^{4}$ Department of Mechanical Engg., University College of Engg. Kothagudem, Dist.Khammam-507101(A.P.) India \\ amarendar_g@rediffmail.com
}

\begin{abstract}
The paper presents the results on the existing diesel engines that can be suitably modified to operate on the dual fuel mode to conserve diesel and also reduce environmental pollution. The conventional fuels, petrol and diesel for internal combustion engines are getting exhausted at an alarming rate, due to tremendous increase in the vehicular population. Further these fuels cause serious environmental problems as they release toxic gases into the atmosphere at high temperatures and concentrations. Some of the pollutants released by the engines are UBHC, CO, NOx, smoke and particulate matter. In view of this and many other related issues, these fuels will have to be replaced by alternative and eco-friendly fuels. A 4-stroke, single-cylinder diesel engine has been considered for the purpose of experimentation. It is modified suitably to run on the dual fuel mode. LPG carburetor is incorporated on the intake side of the engine. The fuel injection system is also altered so that it injects only the pilot fuel. The engine is interfaced with a computer, so that the data could be generated on-line and stored for the off-line analysis. The performance of the engine is evaluated at a constant speed of $1500 \mathrm{rpm}$ under varying load conditions for different proportions of LPG energy. The LPG energy substitution could be done up to $50 \%$ at lower loads and up to $20 \%$ at higher loads. The engine performance is better on pure diesel up to engine loads of about $35 \%$. At higher engine loads, the dual fuel mode is superior to the pure diesel mode of operation. This is true with regard to the emissions also. The smoke density is considerably reduced on dual-fuel operation, compared to that of pure diesel operation. At lower loads, for improved performance, the engine could be operated on pure diesel operation. However for higher loads, the operation could be switched over to the dual fuel mode. The threshold load of transition from diesel fuel mode to the dual fuel mode is found to be about $35 \%$. Dual fuel engines can be conveniently used in various applications, particularly at higher loads.
\end{abstract}

Keywords: Dual-fuel, emissions, gas carburetor, LPG, lower loads, higher loads, performance.

Nomenclature: BSFC - Brake Specific Fuel Consumption; CNG - Compressed Natural Gas; CO - Carbon Monoxide; HSU - Hatridge Smoke Units; LPG - Liquefied Petroleum Gas; NOx - Oxides of Nitrogen; UBHC - Unburnt Hydrocarbons.

\section{Introduction}

There is an urgent need to conserve the conventional fuels, diesel and petrol, so as to reduce the oil import bills of an oil-dependent country and also to mitigate the menace of the environmental pollution. These fuels will have to be replaced by suitable alternative fuels like alcohols and various gaseous fuels. Among various gaseous fuels, CNG, LPG and hydrogen are prominent. Dual-fuel operation is found to be one of the prominent methods of conserving diesel and petrol. Ghazi Karim (1980) has underlined the importance of understanding combustion process in dual-fuel engines with regard to enhanced performance and reduced pollution. In his article, he has critically examined various gaseous fuels with regard to their availability, performance, cost aspects and environmental pollution. Dong Jian et al. (2001) have developed new type of dual-fuel supply system which could able to convert conventional diesel engines in to dual-fuel engines like LPG/Diesel engines and $\mathrm{CNG} /$ Diesel engines. These engines are capable of operating on the diesel baseline mode or dual-fuel mode depending upon the requirements. These diesel-LPG engines have been successfully applied to the diesel baseline buses of public transportation of Guangzhou city, one of the biggest cities of China. Poonia et al. (1999) have experimentally investigated the factors that effect performance of an LPG-Diesel dual-fuel engine. In this work, the effects of intake charge temperature, pilot fuel quantity, exhaust gas recirculation and throttling of the intake on the performance the LPG-Diesel dual-fuel engine have been studied. They have observed that under optimum operating conditions, the brake thermal efficiency of the engine on the dual-fuel mode has increased from $17.5 \%$ to $19.4 \%$ at $20 \%$ load and from $30.2 \%$ to $32 \%$ at $80 \%$ load. The emissions are also reduced significantly on the dual-fuel mode of operation. Amarendar Rao et al. (2008) have performed experiments on a conventional diesel engine operating on dual-fuel mode using diesel and LPG. The experiments have been done at a constant speed of $1500 \mathrm{rpm}$ and under varying load conditions; they have indicated that with the dual-fuel mode of operation, precious diesel could be conserved up to $80 \%$. However, in their work, it could be done only up to $45 \%$ due to severe engine
Research article

(CIndian Society for Education and Environment (iSee)
"Duel fuel engine"

http://www.indjst.org
Rao et al. Indian J.Sci.Technol. 
Indian Journal of Science and Technology

vibrations. The brake power of the engine was found to be about $15 \%$ more on the dual-fuel operation, while the brake specific fuel consumption was found to be about $30 \%$ lower than diesel fuel mode of operation. This could be due to better mixing of air and LPG and improved combustion efficiency. Srinivasa Rao et al. (2005) have made experimental investigations on a single-cylinder water cooled compression ignition engine run on the dual-fuel mode with LPG as the main fuel and diesel as the pilot fuel. The engine was run under different operating conditions of load and speed. The optimum combination of fuels is evaluated at each of the conditions. The exhaust smoke level, exhaust gas temperature and other performance parameters were calculated and a cylinder pressure trace was obtained using a data acquisition system. The cylinder pressure so obtained was thermodynamically analyzed using a computer program and the heat release rate, cylinder gas temperature, equilibrium $\mathrm{CO}$ and NOx concentrations were calculated. In the present work, LPG is used for the partial replacement of diesel in the dual-fuel mode of operation. In this mode, LPG is used as the main fuel to generate the mechanical power and diesel is used as the pilot fuel to initiate the combustion process.

\section{Experimental set-up and data generation}

A single-cylinder, 4-Stroke, water-cooled diesel engine of $5.2 \mathrm{~kW}$ rated power is considered for the purpose of experimentation. The engine is coupled to an eddy-current dynamometer through a load cell. It is integrated with a data acquisition system to store the data for the off-line analysis. The schematic layout of the experimental set up is shown in Fig.1. Cooling water is circulated separately to the engine and the dynamometer at the required flow rates. Necessary provisions are made to regulate and measure the flow rates of the air, fuel and the coolant. Initially, the engine is operated on the diesel baseline mode at a constant speed of 1500 rpm at $10 \%, 20 \%, 30 \%$ etc of the full load up to the full load. At each of these loads, the engine performance parameters are recorded, tabulated and plotted. Then the engine is operated on the dual-fuel mode at different loads using various proportions of diesel and LPG by energy, like $90-10,80-$ 20 and so on. In the $90-10$ mode of operation, $90 \%$ of the heat is supplied due to the combustion of diesel and $10 \%$ of the energy is supplied due to the combustion of LPG. Under these operating conditions, same engine performance parameters are recorded, tabulated and plotted. In the calculations of energy

Research article

CIndian Society for Education and Environment (iSee)

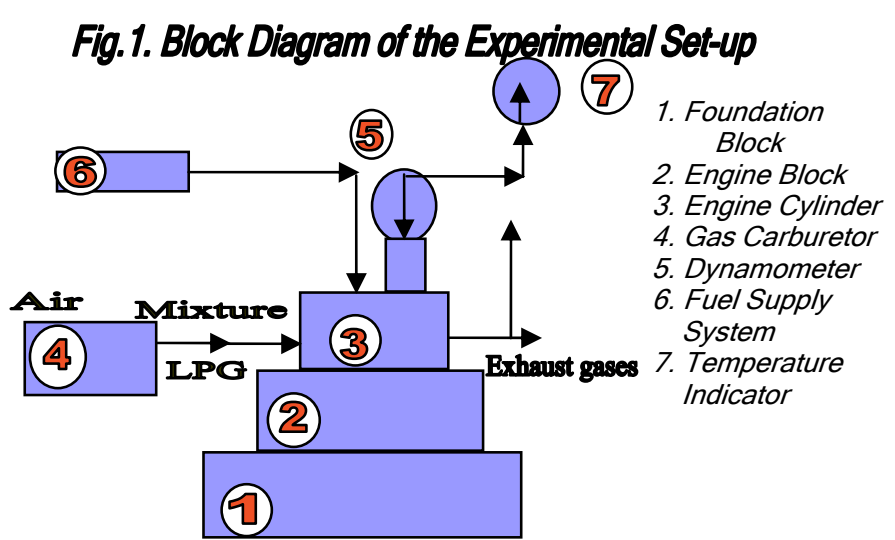

contributions of diesel and LPG, the lower calorific value of diesel is taken as $43000 \mathrm{~kJ} / \mathrm{kg}$ while that of LPG is taken as $45700 \mathrm{~J} / \mathrm{kg}$.

\section{Results and discussion}

The engine operation is observed to be quieter and smoother due to better mixing of LPG and air. At lower loads, the diesel substitution could be done even up to

Fig.2. Effect of load on the brake thermal efficiency

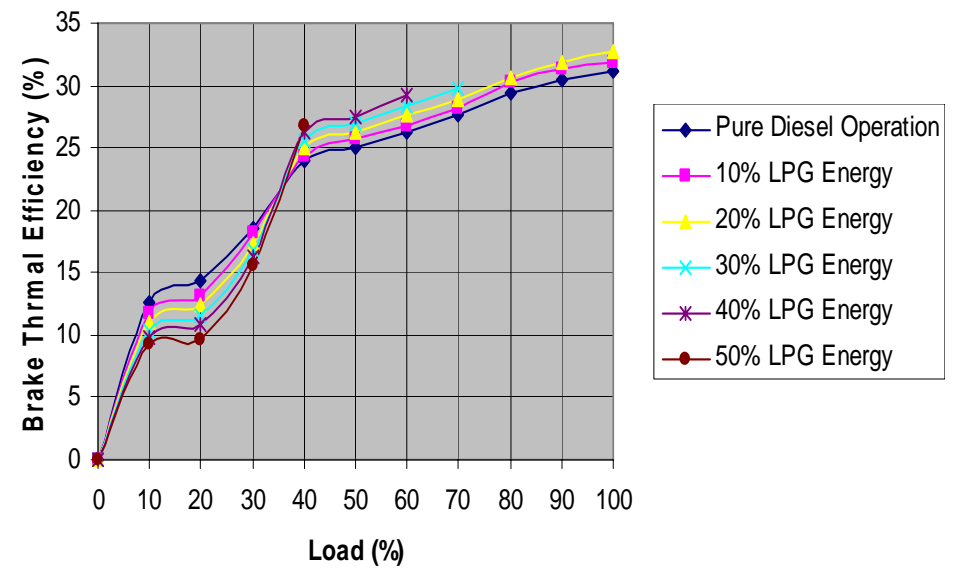

Fig.3. Effect of load on the mechanical efficiency

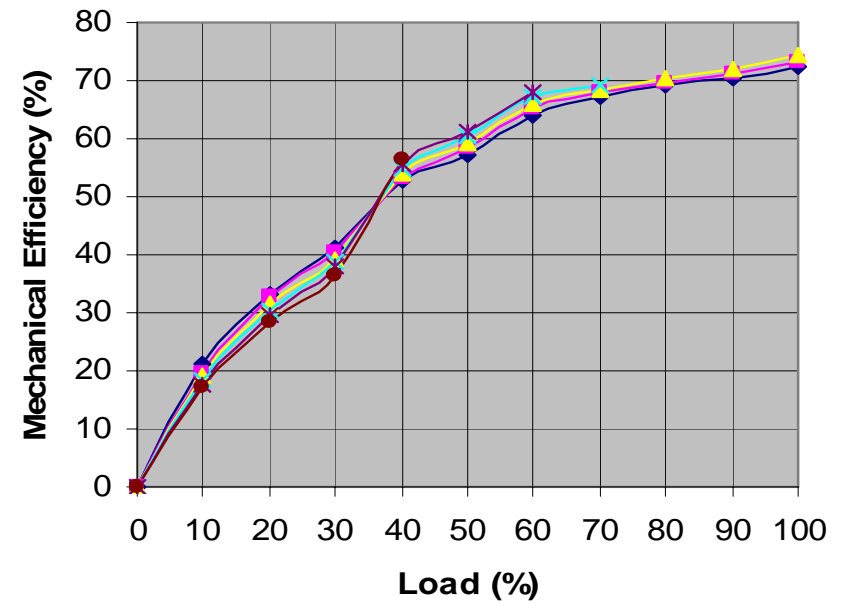

"Duel fuel engine" http://www.indjst.org

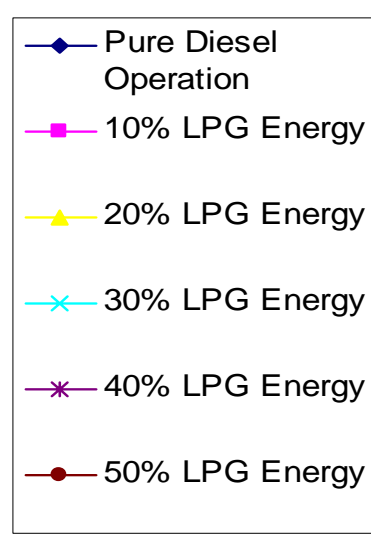

Rao et al. Indian J.Sci.Technol. 
$50 \%$, whereas at higher loads, it could be done only up to $20 \%$. At higher loads, dual-fuel operation has resulted in undue vibrations of the engine with increased LPG energy substitution. Fig.2 represents the effect of load on the brake thermal efficiency of the engine under various modes of operation with varying proportions of LPG energy. It is evident from the figure that at lower loads, diesel base line operation is better than the dual fuel operation. For instance, at $20 \%$ load, the brake thermal efficiency is $14.4 \%$ on diesel baseline operation; it is $12.4 \%$ with $20 \%$ LPG energy and just $9.7 \%$ with $50 \%$ LPG energy. At higher loads, it is observed that dual fuel operation is superior to the diesel baseline operation. At $80 \%$ load brake thermal efficiency with pure diesel operation and dual fuel operation with $20 \%$ LPG energy are $29.4 \%$ and $30.6 \%$ respectively. From Fig.3, it is clear that the mechanical efficiency of the engine increases with an increase in load under all operating conditions. On pure diesel mode at full load, the mechanical efficiency is found to be $72.5 \%$. On dual-fuel mode with $20 \%$ LPG energy the corresponding value is $74.4 \%$, a rise of about $2.6 \%$. At $20 \%$ load, the mechanical efficiency is $33.3 \%$ on pure diesel operation and $31.6 \%$ on dual fuel operation with $20 \%$ LPG energy a drop of about $5.1 \%$. Fig.4. represents the variation of brake specific fuel consumption (BSFC) with the load under different operating conditions. The engine operation is more economical on the pure diesel mode of operation at lower loads. However, at higher loads dual fuel mode of operation is more economical. At $20 \%$ load, BSFC is $0.5801 \mathrm{~kg} / \mathrm{kWh}$ on the pure diesel mode and it is 0.6671 $\mathrm{kg} / \mathrm{kWh}$ on the dual fuel mode with $20 \%$ LPG energy. At $80 \%$ load, the corresponding values are $0.2847 \mathrm{~kg} / \mathrm{kWh}$ and $0.2703 \mathrm{~kg} / \mathrm{kWh}$ respectively. Smoke density is significantly reduced with the dual fuel operation at all the loads, as depicted in Fig.5. As the LPG energy is increased, the smoke density is reduced due to improved combustion characteristics. With 50\% LPG energy, the maximum smoke density is just $4.4 \mathrm{HSU}$, the corresponding value for pure diesel operation is as high as 19.4 HSU which is about 4.5 times to dual-fuel value.

Fig.4. Effect of load on the brake specific fuel consumption
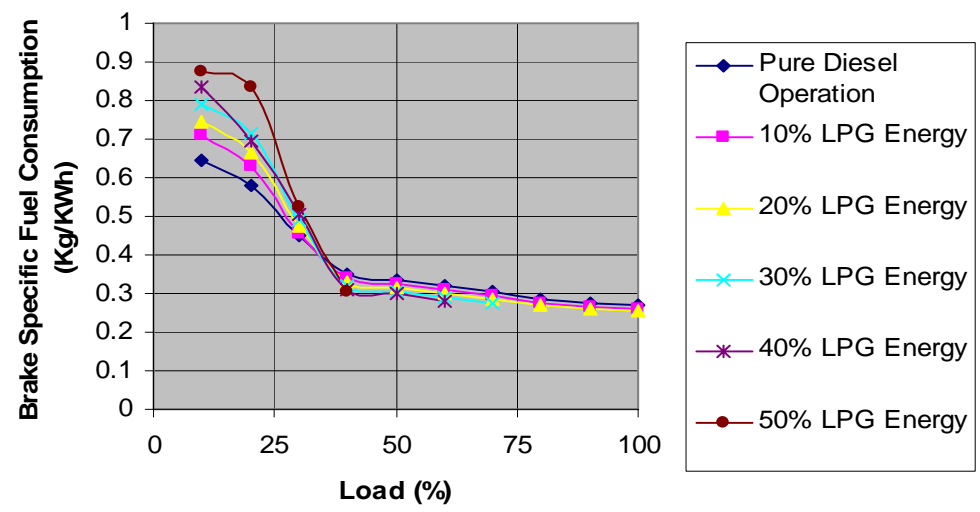

Vol. 3 No. 3 (Mar 2010)

ISSN: 0974- 6846

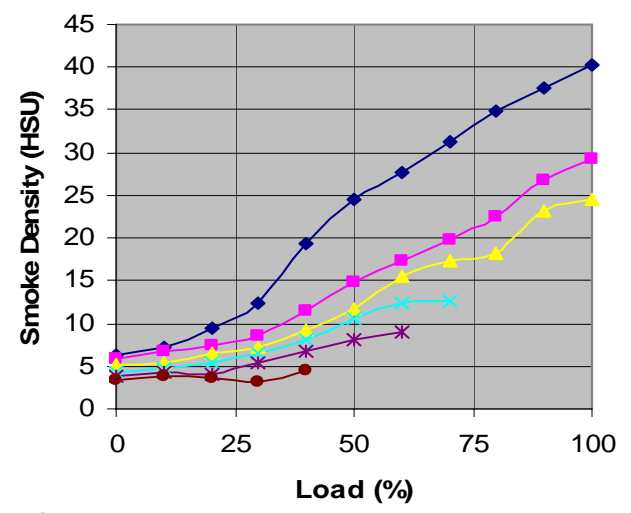

\section{Conclusions}

Dual fuel operation is more convenient and economical for conserving the precious conventional liquid fuels. A diesel base line engine could be operated on the dual fuel mode with minor changes. The following conclusions have been made from the above work.

- The engine operation is smoother and more efficient particularly at high engine loads,

- At lower loads, mechanical, brake thermal efficiencies of the engine are more on the pure diesel mode but at higher loads the reverse is true.

- The engine operation is more economical on the pure diesel mode at lower loads, however at higher loads dual-fuel operation is better.

- The smoke density is negligible on the dual-fuel mode with higher LPG energy substitutions.

- Stationary diesel engines can be conveniently operated on the dual-fuel mode at higher loads.

\section{References}

1. Amarendar Rao G, Sita Rama Raju AV, Mohan Rao CV and Govinda Rajulu K (2008) Experimental investigation of a single-cylinder, four-stroke diesel engine operating on the dual-fuel mode (LPG + Diesel). Intl. J. Scientific Computing. pp: 2(2), 145152.

2. Dong Jian, Gao Xiaohong, Li Gesheng and Zhang Xintang (2001) Study on diesel-LPG dual-fuel engines. SAE Intt. 36-79.

3. Ghazi A Karim (1980) A review of combustion processes in the dual-fuel engine-the gas diesel engine. In: Progressive Energy Combustion Science. pp: 277-285.

4. Poonia MP, Ramesh A and Gaur RR (1999) Experimental investigation of the factors affecting the performance of a LPG-diesel dual-fuel engine. SAE Intl. 1999-01-1123, 1999.

5. Srinivasa Rao BR, Samaga BS and Mohanan R (2005) Combustion studies on LPG-diesel dualfuel engines. Proc. $19^{\text {th }}$ Natl. Conf. Intl. Combustion Engines \& Combustion. Annamalai Univ., Chidambaram. pp:125-130.
Research article

CIndian Society for Education and Environment (iSee)
"Duel fuel engine" http://www.indjst.org
Rao et al. Indian J.Sci.Technol. 